\title{
Impact of Socioeconomic and Demographic Factors on Reproductive Tract Infections during Reproductive Age Group (18-45 Years)
}

\author{
Vasudha Sawant ${ }^{1}$, Sreesti Jaiswal $^{2}$, Manjiri Desai $^{3}$
}

\begin{abstract}
Introduction: The aims of this study were to identify the prevalence of reproductive tract infection (RTI) in married women of reproductive age group (18-45 years), to analyze the impact of socioeconomic and demographic factors on RTIs, to treat the underlying cause.

Materials and methods: A total of 500 women were examined; out of those, 300 women were found to have RTIs and were enrolled for further study and evaluation. Appropriate antibiotics were given to them and then followed.

Results: The study results showed a high prevalence of RTI (60\%). The highest prevalence was found among the age group between 26 years and 29 years, followed by $30-33$ years and $34-37$ years. The most affected women were from rural population (80\%), low socioeconomic group (63.4\%), and illiterate (59\%).

Conclusion: The present study showed a high prevalence of RTI. It needs a further deep study on their literacy and economic factors to evaluate and analyze the impact of these factors on RTIs.

Keywords: Demographic, Reproductive tract infection, Socioeconomic.

Journal of South Asian Federation of Obstetrics and Gynaecology (2019): 10.5005/jp-journals-10006-1699
\end{abstract}

\section{INTRODUCTION}

Reproductive tract infections/sexually transmitted infections (STIs) and nonsexually transmitted infections have become a global threat to the health of the population. Genital tract infection can lead to pelvic inflammatory diseases, infertility, and ectopic pregnancy, and viral infections are liable to cause vulval and cervical cancer. ${ }^{1}$ Reproductive tract infections affect both women and men. Research shows that women are more susceptible than men. In India, self-reported morbidity varies between $39 \%$ and $84 \% .{ }^{2,3}$ About 490 million cases of RTI occur throughout the world, of which 79 million cases occur in India annually. ${ }^{4}$ Reproductive tract infections/STIs are the major reproductive health problems in India. A variety of organisms are involved in causing RTI. The risk of transmission of HIV infection is associated with infections leading to a genital ulcer. In developing countries, RTIs are responsible for psychological and emotional disturbances as well as social and economic stigmas. ${ }^{5,6}$ In many cases, RTIs remain asymptomatic, this causes difficulty in detection and delay in diagnosis and treatment.

Obstetric complications include repeated pregnancy losses intrauterine fetal death, neonatal eye, and throat infection, septicemia.

Majority of complications can be prevented if the women approach to healthcare provider at the earliest.

The aims and objectives:

- To identify, the prevalence RTI among married women of reproductive age group (18-45 years), both pregnant and nonpregnant.

- To observe and analyze the influence of socioeconomic, sociodemographic variables on RTI.

- To evaluate and assess its effect on routine life.

- To treat the underlying cause.
1,2Department of Obstetrics and Gynecology, Dr DY Patil Medical College, Kolhapur, Maharashtra, India

${ }^{3}$ Department of Community Medicine, Dr DY Patil Medical College, Kolhapur, Maharashtra, India

Corresponding Author: Vasudha Sawant, Department of Obstetrics and Gynecology, Dr DY Patil Medical College, Kolhapur, Maharashtra, India, Phone: +91 9008958843, e-mail: dimpy2410@gmail.com

How to cite this article: Sawant V, Jaiswal S, Desai M. Impact of Socioeconomic and Demographic Factors on Reproductive Tract Infections during Reproductive Age Group (18-45 Years). J South Asian Feder Obst Gynae 2019;11(4):246-248.

Source of support: Nil

Conflict of interest: None

\section{Materials and Methods}

This study was undertaken in teaching, tertiary care Hospital, Kolhapur, Maharashtra. The women of the reproductive age group (18-49 years) attending Obst Gyne OPD for various complaints were enrolled in the study. About 500 patients coming for Obst Gyne OPD for any other check-up and treatment between Feb 2017 and Aug 2017 were included in the study. It was an observational study. All married women between the age group of 18-45 years coming for obstetrics and gynecology complaints were asked detailed history, sometimes by asking a leading question. Complaints related to RTIs and STIs were noted.

All women were interviewed about their socioeconomic and sociodemographic, obstetric history, menstrual history, present and previous RTI symptoms. Their general physical examination and other systemic exam were carried out. In OPD per speculum examination was done, any discharge in the vagina noted, its color, amount, the foul smell was evaluated. By doing per vaginal exam,

(-) The Author(s). 2019 Open Access This article is distributed under the terms of the Creative Commons Attribution 4.0 International License (https://creativecommons. org/licenses/by-nc/4.0/), which permits unrestricted use, distribution, and non-commercial reproduction in any medium, provided you give appropriate credit to the original author(s) and the source, provide a link to the Creative Commons license, and indicate if changes were made. The Creative Commons Public Domain Dedication waiver (http://creativecommons.org/publicdomain/zero/1.0/) applies to the data made available in this article, unless otherwise stated. 
any tenderness in the vaginal walls and fornices, any palpable mass was noted. The women who were suspected of having infection clinically, wet mount; gram staining of vaginal discharge was carried. In all women, urine routine microscopic examination was done. Also, their serum VDRL test was done. The complete history of each patient was then analyzed.

\section{Statistical Analysis}

Graphs are prepared in MS Excel 2007.

All the qualitative variables are compared by using the Chisquare test. Probability value $(p<0.05)$ is considered statistically significant. Graphpad quickcalcs software is used for analysis.

\section{Observations and Results}

A total of 500 patients were interviewed and undergone a clinical evaluation, laboratory investigations.

Amongst those 300 patients were diagnosed as having RTI clinically. The present study showed a $60 \%$ prevalence of RTI. Those patients only were included in the study and further evaluated. The majority of the age group involved was between the age of 26 years and 29 years, which was contributing about $32 \%$, followed by the age group of $30-33$ years, which was about $28 \%$. The less affected (2\%) group was between the age of 18 years and 21 years (Table 1).

By Chi-square test incidence of RTI is significantly more in age groups between 26 years and 29 years, 30 years and 33 years, and 34 years and 37 years, respectively.

Among the study, population $80 \%$ were residing in a rural area shows a significantly higher incidence of RTI in rural populations as compared to the urban population. Regarding literacy, the study population suffering from RTI was 59\% illiterate, that means illiterate women due to lack of knowledge related to genital hygiene suffer from RTI (Tables 2 and 3).

Further, there is a significantly higher incidence of RTI among low socioeconomic groups $63.4 \%$.

The predominant clinical feature was lower backache (26.6\%), vaginal discharge (23.3\%), and pain in the lower abdomen (21.6\%). While the incidence of itching around the vaginal area, burning micturition was $13.3 \%$ and $8.3 \%$, respectively. Dyspareunia was found in 45 women.

Patients were treated with appropriate antibiotics. After completion of treatment for RTI/STI, they were followed and found that their symptoms were relieved (Table 4).

Table 1: Prevalence of reproductive tract infection

\begin{tabular}{lll}
\hline Total number of cases & No. of RTI cases & Prevalence of RTI \\
\hline 500 & 300 & $60 \%$ \\
\hline
\end{tabular}

Table 2: Age-wise distribution of reproductive tract infection cases

\begin{tabular}{lrc}
\hline Age GP & (\%) & No. of cases \\
\hline $18-21$ & 2 & 6 \\
$22-25$ & 10 & 30 \\
$26-29$ & 32 & 96 \\
$30-33$ & 28 & 84 \\
$34-37$ & 18 & 54 \\
$38-41$ & 5 & 15 \\
$42-45$ & 5 & 15 \\
Total & 100 & 300 \\
\hline
\end{tabular}

Table 3: Socioeconomic and demographic data

\begin{tabular}{lccc}
\hline Variable & No. of cases & $(\%)$ & \\
\hline $\begin{array}{l}\text { Residence } \\
\quad \text { Rural }\end{array}$ & 240 & 80 & $(p<0.0001)$ \\
$\quad$ Urban & 60 & 20 & \\
Literacy & & & \\
$\quad$ Literate & 122 & 41 & $(p=0.0012)$ \\
$\quad$ Illiterate & 178 & 59 & \\
$\begin{array}{l}\text { Occupation } \\
\quad \text { Housework }\end{array}$ & 240 & & \\
$\quad$ Job/Business & 60 & 80 & $(p<0.0001)$ \\
Monthly income & & 20 & \\
$\quad<10,000$ & 190 & 63.4 & $(p<0.0001)$ \\
$>10,000$ & 110 & 36.6 & \\
\hline
\end{tabular}

Table 4: Clinical symptoms

\begin{tabular}{lll}
\hline & (\%) & No. of cases \\
\hline Backache & 26.66666667 & 80 \\
Vaginal discharge & 23.33333333 & 70 \\
Low abdominal pain & 21.66666667 & 65 \\
Itching around vaginal area & 13.33333333 & 40 \\
Burning micturition & 8.333333333 & 25 \\
Dyspareunia & 4 & 12
\end{tabular}

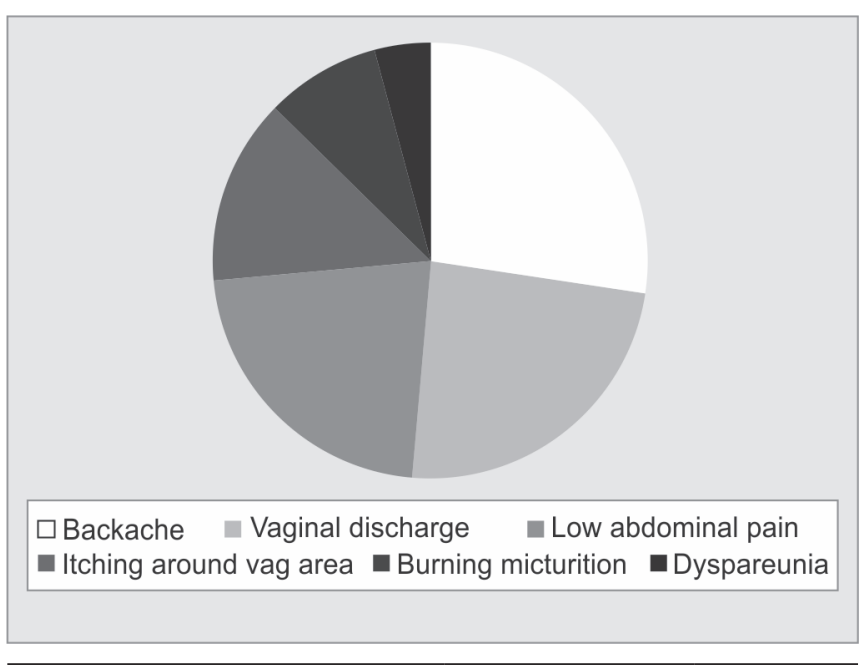

\section{Discussion}

The present study shows that the prevalence of $\mathrm{RTI}$ is about $60 \%(300 / 500)$ in patients attending Obst Gynae OPD. Out of these, $53.41 \%$ were having symptoms suggestive of RTI, while $46.6 \%$ were asymptomatic. This reflects that the women having complaints of genital infections had kept the history hidden from family members; majority of women gave a history of symptoms suggestive of RTI, after asking a leading question. Those who gave the history of symptoms suggestive of RTls were having disease progressed to a nonbearing extent. Previous community-based studies show a prevalence between $15 \%$ and $80 \% .^{7-11}$ Ramia et al. study result showed a prevalence of RTI (28.2\%). ${ }^{12}$ Our study shows that the highest prevalence of C. albicans was $41 \%$ in pregnant women. ${ }^{13}$ 
The present study objective was to observe the influence of socioeconomic status on RTI. Our study showed that 63.3 of patients with RTI had monthly income of $<10,000$, and $36.6 \%$ of patients with RTI had monthly income $>10,000$. One study by Dameru showed that low-income socioeconomic status as a risk factor for RTI., ${ }^{9,14}$

The present study revealed that $59 \%$ of patients were illiterate, and $41 \%$ were literate. This shows that literacy does not have any influence on RTI. On the contrary, Dameru reported that women with informal education had more RTI. Similarity, one study conducted by Kafle et al. ${ }^{15}$ shows a similar result as that of Dameru.

In the present study, $11.2 \%$ of patients were having a history of previous abortion.

Regarding symptoms, $53.3 \%$ of patients were symptomatic, while $46.6 \%$ were asymptomatic. Among the symptoms, $50 \%$ were having backache, which they were thinking nonspecific. Different types of vaginal discharge were present in $43.7 \%$ of patients, while $40.6 \%$ were having pain in lower abdomen. Itching of vulva and around vagina was present in $25 \%$ cases, and burning micturition was compliant in $15.6 \%$ cases. No one was having genital ulceration or inguinal swelling. One study in Nigeria reported $57.7 \%$ of women had vaginal discharge, vulval itching, and pain in lower abdomen. ${ }^{16}$

The study states that women during the reproductive age group must be educated regarding genital hygiene, especially during menses. Awareness must be created among women by giving health talks related to RTI. The confidence should be build up to come forward and tell any minor complaints also to healthcare provider so that the conditions are diagnosed early, and treatment can be given at earlier stage, due to which morbidity due to genital infection in the form poor general health, hesitation in talking about genital complaints and overall ill effect of RTI on their life can be minimized.

This study was hospital-based so, it has limitations. Further community-based studies should be extended to all levels of residential areas like slum areas in urban, working women who work as laborers to women who are on higher post, women staying in villages.

\section{Conclusion}

Above study shows that socioeconomic status and literacy play an important role in developing RTI/STI. Basic awareness related to RTI should be created among these populations. The most common symptom was backache and vaginal discharge. Health education talks and training of personnel and genital hygiene need to be carried out among rural areas, low socioeconomic groups, and illiterate populations.

\section{References}

1. Kumar S, Padubidri VG, Daftary SN. Howkins and Bourne Shaw's Textbook of Gynecology. Sexually transmitted diseases, Ch. 11.2015. p. 155.

2. Bany RA, Bang AT, Bailule M, et al. High prevalence of gynecological diseases in rural Indian women. Lancet 1989;1:285-288. DOI: 10.1016/ s0140-6736(89)91438-4.

3. Lathak Kanani SJ, Maitra N, Bhattacharya RV. Prevalence of clinically detectable gynaecological morbidity in India. Results of four community based studies. Family Welf 1997;43(4):8-16.

4. Rizwan SA, Roth R, Vivek G, et al. KAp study of STISI RTIS among married women in rural Haryana. Indian Dermatology Online Journal 2015;6(1):9-12. DOI: 10.4103/2229-5178.148919.

5. Low N, Broutet N, Adu-Sarkodie Y, et al. Global control of sexually transmitted infections. Lancet 2006;368(9551):2001-2006. DOI: 10.1016/S0140-6736(06)69482-8.

6. World Health Organization, Guidelines for the management of sexually transmitted infections. Available: http:/?www.who. int/hiv/sti/en/STIGuidelines2003.pdf. Last accessed February 2011 2003.

7. Ravi RP, Kulasekaran RA. Care seeking behaviour to accessing services for sexual health problem among womens in Rural area of Tamil Nadu state in India. J Sexually Transmitted Dis 2014;2014:292157.

8. Thekdin KP, Patel NK, Patel KG, et al. Health seeking attitude of women regarding reproductive tract infections in a rural area of Surendranagar district. Int J Res Med Sci 2013;1(4):552-556. DOI: 10.5455/2320-6012.ijrms20131143.

9. Dameru PP. Prevalence and factor associated with reproductive tract infections among married women of reproductive age in Nepal. Asian J Med Sci 2012;2(1):46-49.

10. Philip PS, Benjamin Al, Sengupta P. Prevalence of symptoms suggestive of reproductive tract infections/sexually transmitted infections in women in urban area of Ludhiana. Indian J sexually Transmitted Dis 2012;56(3):204-209.

11. Parashar A, Gupta B, Bhardwaj A, et al. Prevalence of RTls among women of reproductive age group in Shimla city. Indian J Community Med 2006;31(1):15-17. DOI: 10.4103/0970-0218.54924.

12. Ramia S, Kobeissi L, El Kak F, et al. Reproductive tract infections (RTIs) among married non-pregnant women living in low-income suburb of Beirut, Lebanon. J Infect Dev Ctries 2012;6(9):680-683. DOI: 10.3855/ jidc.1903.

13. Ibrahim SM, Bukar M, Mohammed Y, et al. Prevalence of vaginal candidiasis among pregnant women with abnormal vaginal discharge in Maiduguri. Niger J Med 2013;22(2):138-142.

14. Kazi YK, Shenoy AG, Velhal G, et al. Reproductive and sexual tract infections among married female youth in an urban slum of Mumbai. Natl J Community Med 2013;4(1):10-14.

15. Kafle P. Prevalence and factor associated with reproductive tract infections in Gongolia village, Rupandehi district. Nepal Adv Public Health 2016;2016:8063843. DOI: 10.1155/2016/8063843.

16. Rabiu KA, Adewunmi AA, Akinlusi FM, et al. Female reproductive tract infections: understandings and care seeking behaviour among women of reproductive age in Logos, Nigeria. BMC Women Health 2010;10:8-10. DOI: 10.1186/1472-6874-10-8. 